\title{
Prevalence and characteristics of COPD among residents in an urban informal settlement in Dar es Salaam, Tanzania
}

Ngweina Francis Magitta ( $\square$ ngweina.magitta@gmail.com )

University of Dar es Salaam

Meshack Denson Shimwela MD

Amana Regional Referral Hospital

Sapna Jitendra Madas

Chest Research Foundation

Julius David Mwaiselage MD

Ocean Road Cancer Institute

Anna Alphonce Sanga MD

Muhimbili National Hospital

Komalkirti Keshavkiran Apte

Chest Research Foundation

Lucy Andrew Namkinga MSc Pharm

University of Dar es Salaam

Sundeep Santoshi Salvi MD

Chest Research Foundation

\section{Research article}

Keywords: chronic obstructive pulmonary disease, prevalence, risk factors, indoor pollution, biomass fuel, informal settlement, urban health

Posted Date: October 4th, 2019

DOl: https://doi.org/10.21203/rs.2.15525/v1

License: (c) (i) This work is licensed under a Creative Commons Attribution 4.0 International License.

Read Full License 


\section{Abstract}

Background: COPD is an important public health problem globally. To-date, indoor air pollution resulting from biomass fuel use is an important risk factor for COPD, particularly in Africa. The poor communities in informal settlements in major cities are likely to be exposed to higher pollution rates and could disproportionately develop COPD.

Methods: We collected demographic data, respiratory symptoms and exposure history to air pollution using BOLD validated questionnaire and further performed spirometry using NDD EasyOne ${ }^{\mathrm{TM}}$ spirometer, with COPD diagnosed based on a post-bronchodilator $\mathrm{FEV}_{1} / \mathrm{FVC}<70 \%$. The study was approved by the National Ethics committee.

Results: A total of 1021 participants completed the questionnaire and had acceptable post-bronchodilator spirometry [(861 female, $66.70 \%)$ ], with mean age of $52.16 \pm 11.59$ years. About $15.48 \%$ of respondents were smokers, of whom $6.46 \%$ were current smokers and $16.67 \%$ had significant nicotine dependency. Of all respondents, $11.71 \%$ reported living with a smoker and $5.31 \%$ reported a history of tuberculosis. The overall prevalence of COPD was estimated at $8.13 \%$ [(14.2\% male, $5.14 \%$ female $)$, and found to be associated with age $(p=0.005)$, gender $(p=0.001), B M I(p=0.001)$ and smoking status $(p=0.001)$. Over $98 \%$ of respondents reported significant exposure to biomass fuel. Over $78 \%$ of COPD patients had mild to moderate obstruction and the female had comparatively severe obstruction.

Conclusion: In this population, COPD is relatively low compared to previous reports in Africa. Though multiple risk factors are responsible for COPD development, indoor pollution remains the most important factor. In this regard, access to affordable clean energy for domestic use is the most important strategy for COPD control.

\section{Background}

Chronic obstructive pulmonary disease (COPD) is a disease characterized by irreversible airway limitation. Estimates from Global Burden of Diseases (GBD) 2017 report indicate that COPD was responsible for over 3 million deaths and 5 million years of life lost (YLL) due to premature mortality[1, 2]. There are limited data on COPD in Africa[3]. Findings from two recent population-based studies conducted in rural settings in Uganda and Tanzania have indicated the comparable prevalence rates of $16.2 \%$ and $17.5 \%$ respectively $[4,5]$. In both studies, exposure to biomass fuel was reported in nearly all respondents; representing the major risk factor associated with COPD in Africa [6-8].

The current rapid socio-economic transition in Africa, characterized by increased rural-urban migration, widespread informal settlements and congestion in major cities overburdens urban health metabolism [9]. In Africa, gross lack of infrastructural and financial resources together with limited expertise hinders investment in clean energy. Thus, many countries rely on fossil energy and biomass fuels for industrial operations and domestic use [10]. Regrettably, in major cities, overcrowding accompanied with poor housing together with air pollution potentially contribute to the risk of developing COPD $[3,11]$. Indoor 
pollution and other factors, besides tobacco smoking, are well documented COPD risk factor in Africa [3, $8,12]$. Noteworthy, the use of biomass fuel is a well demonstrated causality $[12,13]$. Overall, both outdoor and indoor house pollution contribute to about 600,000 deaths per year in major cities in Africa.

Regrettably, women and children are a greater risk of exposure to indoor pollution who routinely spend long hours in these houses during preparation of food for their families [14-18].

The only gene well characterized COPD susceptibility gene is SERPINA1, encoding alpha- 1 antitrypsin (AAT). In a recent study, mutations of AAT gene were found in $7.2 \%$ of patients with COPD, highlighting the importance of mutational screening [19]. In addition, several longitudinal studies, meta-analysis and family-based linkage studies have reported COPD susceptibility variants in several genes involved in inflammation and oxidative stress [20,21]. The available global genome-wise association studies (GWAS) have identified COPD susceptibility variants near hedgehog interacting protein (HHIP), and cholinergic nicotinic acetylcholine receptor (CHRNA3/5) [22]. Currently, the mitigation for air pollution in order to reduce associated deaths through provision of affordable clean energy as well as reduction of negative environmental impact has become an important global agenda as outlined in Sustainable Development Goal 7. This study was conducted in Dar es Salaam city to determine the prevalence and characteristics of COPD in an informal urban setting.

\section{Methods}

\section{Study objectives and design}

We aimed to determine the prevalence rate of COPD and exposure to risk factors using validated BOLD survey questionnaires (www.boldstudy.org) and NDD EasyOne ${ }^{\mathrm{TM}}$ spirometry (nnd medizintechnick AG, Zurich, Switzerland) in the purposely selected informal urban settlement in Dar es Salaam, Tanzania. We conducted a population-based cross-sectional descriptive survey involving eligible adults aged $\geq 30$ years, residing in the local area for at least 6 months. This study was conducted between July 2017 and November, 2017. The study was approved by the Tanzania National Ethics Committee.

\section{Data collection}

A standard validated BOLD questionnaire was used for assessment of exposure to risk factors, respiratory symptoms together with activity limitation for COPD. In parallel, COPD was assessed using spirometry based on BOLD protocol. In addition, all basic demographic data and personal particulars together with co-morbidities, as well as work-up for clinical severity and control of COPD were recorded. Eligible participants aged $\geq 30$ years underwent testing for spirometry. The diagnosis of COPD was made based on a history of exposure to risk factors and the presence of airflow limitation that was not fully reversible, with or without the presence of symptoms. A post-bronchodilator $\mathrm{FEV}_{1} / \mathrm{FVC}<70 \%$ and a postbronchodilator $\mathrm{FEV}_{1}<80 \%$ predicted confirms the presence of airflow limitation that is not fully reversible. All participants were evaluated for airflow limitation using NDD EasyOne ${ }^{\mathrm{TM}}$ spirometer repeated after 
inhalation of a short-acting bronchodilator, $200 \mu \mathrm{g}$ albuterol. The spirometry measurements used in the analysis included $\mathrm{FVC}, \mathrm{FEV}_{1}, \mathrm{FEV}_{6}$, peak flow, and total expiratory time. This will allowed comparison of $\mathrm{FEV}_{1} / \mathrm{FVC}$ and $\mathrm{FEV}_{1} / \mathrm{FEV}_{6}$ as measures of airflow limitation. Patients diagnosed to have COPD were assessed for severity and activity limitation using Modified Medical Research Council Dyspnoea Scale and COPD Assessment Test (CAT) respectively.

\section{Statistical analysis}

The collected data were initially on paper questionnaires were double-entered on Epidata software (CDC, Atlanta, GA, USA) and later exported to SPSS version 20 (IBM, NY, USA). Data were exported from spirometers in appropriate format for manual inspection and validation of spirographs. We used Chisquare test to detect differences in the frequencies of categorical characteristics. Where necessary, we used student, $\mathrm{t}$-test to detect differences in the mean values between the groups. Selected demographic variables, respiratory symptoms, biomass fuel use and cigarette smoking were tested for associations. The relationships between COPD and associated risk factors were analysed using Chi-square test. A p value of $<0.05$ was used to indicate statistical significance.

\section{Results}

\section{Demographic characteristics}

As shown in Table 1, we recruited a total of 1021 [340 male, 681 female] participants with a mean age of $52.16 \pm 11.59$ years. It was revealed that over $99 \%$ of the participants were Africans with only a few being of Arabic and Indian descents. About $73.56 \%$ of the respondents had attained primary education and none had achieved four-year college or university education. The respondents had a mean Body Mass Index (BMI) of $25.13 \pm 5.70$, of whom about $10.29 \%$ were underweight and $46.37 \%$ were at least overweight. A total of 158 respondents were ever-smokers accounting for the prevalence of cigarette smoking of $15.48 \%$ while the prevalence of current smoking was estimated at $6.46 \%$.

As detailed in Figure 1, study respondents were found to have multiple co-morbid conditions including hypertension, tuberculosis, and heart disease at the prevalence of $24.49 \%, 5.31 \%$ and $4.80 \%$ respectively. Moreover, $11.71 \%$ were living in the same house with another person who was smoking cigarette and $0.69 \%$ of the respondents were already diagnosed to have emphysema/chronic bronchitis or COPD by a healthcare professional prior to the study. Furthermore, it was reported that $1.96 \%$ of the respondents were hospitalized for a breathing problem during childhood.

As displayed in Figure 2, there are exposures to three major risk factors for developing COPD among the respondents. Over $98 \%$ of the respondents were exposed to biomass fuel while exposure to dusty jobs and cigarette smoking accounted for nearly $37 \%$ and over $15 \%$ respectively. 


\section{Prevalence and risk factors of chronic obstructive pulmonary disease (COPD)}

As highlighted in Table 2, the overall prevalence of COPD was estimated at 8.13\% [(14.2\% male, and $5.14 \%$ female)]. As depicted in Table 2, COPD was found to be significantly associated with gender ( $\mathrm{p}=$ $0.001)$, age $(p=0.005), \operatorname{BMI}(p=0.001)$ and cigarette smoking status $(p=0.001)$.

In Table 3, it is shown that about $47 \%$ of the COPD patients had moderate obstruction and $21.7 \%$ had severe to very severe obstruction. Further, it was noted that, of all COPD patients, about $57.8 \%$ were males. Moreover, the severity of obstruction was found to increase with age. The prevalence was lowest, $2.4 \%$, in 30-40 years age-group while the highest prevalence, $66.3 \%$, was recorded among those aged 60 years and above.

Figure 3 show that the majority of COPD patients were in the age-group 60 years and above, with age related trend. The majority of male patients with COPD had mild to moderate obstruction, accounting for over $78 \%$, while the majority of female were found to have severe to very severe obstruction. Overall, the majority of COPD patients had moderate obstruction.

As shown in Figure 4, the over a third of patients with COPD presented with cough, wheezing and breathlessness. Moreover, about a quarter of patients with COPD presented with phlegm and shortness of breath. However, there were no statistical differences in symptoms between COPD patients and those respondents without COPD. Moreover, is shown that when activity limitation in patients with COPD were assessed based on CAT, over $57 \%$ reported walking slowly, over $21 \%$ reported stopping for breath, about $29 \%$ reported experiencing shortness of breath while walking 100 yards and over $14 \%$ reported experiencing shortness of breath at rest.

The prevalence of cigarette smoking was estimated at $15.48 \%$, as shown in Table 1 . Of all ever smokers, 66 respondents representing $6.45 \%$ were current smokers, of whom $16.6 \%$ had significant nicotine dependency, as indicated in Table 4.

Figure 5 displays possible risk of passive exposure and promotional activities of tobacco and cigarette smoking. It was reported by over $47 \%$ that cigarette smoking is allowed at work. A number of promotional activities were reported including brand name or logo of cigarette on clothes and other items, provision of free samples of cigarettes, reduction of cigarette prices and sponsorship of sporting events at the prevalence of $28 \%, 24 \%, 23 \%$ and $19 \%$ respectively.

\section{Discussion}

The current study revealed COPD as a substantial public health problem in Tanzania. The observed COPD prevalence is almost half of the figures previously reported by our group and other studies conducted elsewhere in Africa. The population-based study conducted by Magitta et al in Tanzania reported the prevalence of $17.5 \%$ using similar criteria [4]. Similarly, the study conducted by van Gemert et al in 
Uganda reported the prevalence of $16.2 \%$ [5]. The reason for observed low prevalence of COPD in the current study is not well known. In this study, both the age and gender do not appear to explain the observed differences since the mean age of the study population and the proportion of male-to-female ratio were similar to the previous reports. However, the higher prevalence of ever-smokers in the previous studies could, in part explain the observed differences due to the "double-risk" of COPD. In parallel, a closer observation of the proportions of severity of COPD categories based on GOLD criteria reveals fewer patients with severe-to-very severe disease. The increased mortality of patients with severe COPD, in the context of lack of affordable healthcare, could partly explain the observed low prevalence in the current study.

In line with other studies conducted elsewhere, COPD was found to be associated with age $[4,5,23]$. This finding is both epidemiologically and biologically plausible due to cumulative risk over time-thus highlighting increased risk of COPD in older respondents. Noteworthy, both male gender and cigarette smoking status were found to be associated with COPD similar to other previous studies. However, while cigarette smoking is common among males, female are typically at increased of exposure to biomass fuel-as due to existing socio-cultural constructs they are responsible for cooking and preparation of meals and thus at increased risk of exposure to biomass fuel and subsequent development of COPD. Thus, the existing cross- exposure could balance the exposure risk related to gender.

Over three-quarter of COPD patients had mild-to-moderate obstruction and only a quarter comprised patients with severe-to-very severe obstruction. The majority of male had moderate obstruction while the majority of female had severe obstruction. The COPD severity was noted to increase with age, with more patients with severe disease in the 60+ age-categories. These findings are in agreement with other studies conducted elsewhere. This observation, are theoretically related to the cumulative risk to exposure to COPD risk factors which are fundamentally time-dependent. The major symptoms of COPD were cough, wheezing and breathlessness. Other symptoms were shortness of breath and phlegm production. These symptoms are similar to the findings obtained from studies reported elsewhere. Moreover, assessment of activity limitation, based on CAT revealed shortness of breath at 100 yards in about $29 \%$ and shortness at rest in over $14 \%$.

COPD develops in a sub-set of individuals with exposure to inhalant particles or noxious gases highlighting the role of ill-defined susceptibility genes. Though not well characterized, several genes involved in oxidative stress and inflammation are likely to confer susceptibility risk and thereby mediating airway smooth muscle injury and remodeling [24-26]. Of all genes, the only gene that is known to influence COPD susceptibility is SERPINA1, encoding AAT. Except for few studies, AAT mutations have not been well characterized in African populations. In the context of genetic predisposition, other factors such as cigarette smoking and exposure to air pollution acts singly or multiply in synergy to increase the risk of developing COPD.

In our study, exposure to biomass fuel was reported by almost all respondents. These findings are in congruency with multiple studies conducted in Africa. Thus, biomass exposure appears to be a major risk 
factor, other than cigarette smoking, for COPD development in Africa [27]. However, in Africa, patients may be exposed to multiple risk factors which synergistically act to accelerate COPD development and progression [28-30]. For instance, individuals who smoke cigarette may be exposed to ambient/indoor air pollution and/or occupational exposure to dusty jobs. Similar to other findings from studies conducted in developing countries, the multiplicity of risk factors could be contribute to COPD risk in our study in which over $37 \%$ of respondents were occupationally-exposed and $15 \%$ were cigarette smokers [29]. It was further revealed that about $17 \%$ of cigarette smokers had significant nicotine dependency. This subset of respondents is not likely to quit smoking, thus exposing them to increased risk of developing COPD and other tobacco-related morbidities. A recent review by Magitta, NF revealed poor uptake of tobacco control strategies in many countries in sub-Saharan Africa [31]. The existing lack of smoking cessation programs coupled with weak strategies on tobacco ban is likely to accelerate tobacco consumption and development of COPD and other morbidities associated with tobacco consumption.

Our study reported several co-morbidities among all respondents which included hypertension, tuberculosis, heart failure and diabetes at a prevalence of $24.4 \%, 5.31 \%, 4.80 \%$ and $4.60 \%$ respectively. None of these co-morbidities were found to be associated with the risk of developing COPD. However, other studies conducted elsewhere have reported an important role of history of pulmonary TB to increase risk of future COPD development through multiple pathogenic mechanisms [28, 32, 33]. Though not assessed in our study, HIV infection could be contributing factors to the risk of COPD in this marginalized population, where it is likely to higher than the general population. The interplay between increased risk of COPD and HIV infection has been described and reported by multiple previously conducted studies [28]. Again, patients with HIV often are at greater risk of TB and often suffer multiple episodes, thus contributing to airway and pulmonary injuries and increased risk of COPD. Thus, increased HIV care and coverage of antiretroviral therapy could contribute to COPD prevention in Africa.

\section{Conclusion}

Rapidly growing cities in Africa often faces multiple challenges including those that have negative impact on health. The current study highlights the hidden burden of COPD resulting from exposure to multiple risk factors in informal, unplanned urban settlements. There is urgent need to address the risk factors in order to curb COPD epidemics in Africa. These strategies should include improved housing, reduction of indoor pollution through provision of subsidized affordable clean energy as well as provision of services related to smoking cessation and therapy for dependency. There should be purposeful strategies for early diagnosis of COPD so that appropriate management can be offered to prevent morbidity and premature mortality.

\section{List Of Abbreviations}

AAT

Alpha-1 antitrypsin deficiency 
Body Mass Index

BOLD

Burden of Obstructive Lung Disease

CAT

COPD assessment test

CHRNA3/5

cholinergic nicotinic acetylcholine receptor

COPD

Chronic Obstructive Pulmonary Disease

FEV

Forced Expiratory Volume

FVC

Forced Vital Capacity

GBD

Global Burden of Diseases

GOLD

Global Obstructive Lung Disease

GWAS

Genome-wide association studies

HHIP

Hedgehog interacting protein

HIV

Human Immunodeficiency Virus 
ICSU

International Council for Science

LIRA2030

Leading Integrated Research in Africa 2030 Agenda

MRC

Medical Research Council

NASAC

Network of African Science Academies

NDD

new diagnostic design

SERPINA1

Serine proteinase inhibitor, clade A, member 1

SOB

Shortness of breath

SPSS

Statistical package for social science

TB

Tuberculosis

YLL

Years of Life Lost

\section{Declarations}

\section{Ethics approval and Consent to participate}

This study was approved by the National Institute for Medical Research (NIMR) Ethics Committee in Tanzania and conducted in accordance with Helsinki Declaration on the study on human subjects. All participants consented to participate in the study. 


\section{Consent to publish}

All participants were requested for and consented for the permission to publish the study findings.

\section{Availability of data and materials}

All raw data pertaining to this study are stored at an institutional repository with secure back up. Both raw and processed data can be retrieved and made available to the third party upon request according to the institutional regulations.

\section{Competing interests}

All authors declare no competing interests.

\section{Funding}

This study was conducted by the University of Dar es Salaam in collaboration with other investigators through financial support from Network of African Science Academies (NASAC) and International Council for Science (ICSU) through Leading Integrated Research for Agenda (LIRA) 2030 in Africa.

\section{Authors' contributions}

NFM conceived and designed the study. The study was reviewed by MDS, JDM, KKA, SJM, LAN and SSS. NFM and AAS provided training and supervised fieldwork activities together with data entry. KKA performed spirometry quality check and SJM performed basic statistical analysis. NFM prepared the results and wrote the first draft of the manuscript. All investigators reviewed the final version of the manuscript.

\section{Acknowledgements}

We are grateful to BOLD UK for the permission to use their study protocol. We thank administrative and health authorities in Ilala district and Vingunguti administrative ward for the permission to conduct this study. We are also grateful for the support from all fieldworkers and staff involved in this study. We are greatly indebted to all study participants.

\section{References}

1. Global, regional, and national age-sex-specific mortality for 282 causes of death in 195 countries and territories, 1980-2017: a systematic analysis for the Global Burden of Disease Study 2017. Lancet. 392(10159): p. 1736-1788. 
2. Global, regional, and national disability-adjusted life-years (DALYs) for 359 diseases and injuries and healthy life expectancy (HALE) for 195 countries and territories, 1990-2017: a systematic analysis for the Global Burden of Disease Study 2017. Lancet. 392(10159): p. 1859-1922.

3.Salvi, S., The silent epidemic of COPD in Africa. Lancet Glob Health. 3(1): p. e6-7.

4.Magitta, N. F., et al., Prevalence, risk factors and clinical correlates of COPD in a rural setting in Tanzania. Eur Respir J. 51(2).

5.van Gemert, F., et al., Prevalence of chronic obstructive pulmonary disease and associated risk factors in Uganda (FRESH AIR Uganda): a prospective cross-sectional observational study. Lancet Glob Health. 3(1): p. e44-51.

6.Fullerton, D. G., S. B. Gordon, and P.M. Calverley, Chronic obstructive pulmonary disease in non-smokers. Lancet, 2009. 374(9706): p. 1964-5; author reply 1965-6.

7.Hopkinson, N. S. and M. I. Polkey, Chronic obstructive pulmonary disease in non-smokers. Lancet, 2009. 374(9706): p. 1964; author reply 1965-6.

8.Salvi, S. S. and P. J. Barnes, Chronic obstructive pulmonary disease in non-smokers. Lancet, 2009. 374(9691): p. 733-43.

9.Keivani, R., A review of the main challenges to urban sustainability. International Journal of Urban Sustainable Development 2010. 1(1-2).

10.Douglas F. Barnes, W. F., Biomass Energy and the Poor in the Developing World. Journal of International Affairs, 1999. 53(1): p. 237-259.

11.Burney, P., et al., Chronic obstructive pulmonary disease mortality and prevalence: the associations with smoking and poverty-a BOLD analysis. Thorax. 69(5): p. 465-73.

12.Siddharthan, T., et al., Association between Household Air Pollution Exposure and Chronic Obstructive Pulmonary Disease Outcomes in 13 Low-and Middle-Income Country Settings. Am J Respir Crit Care Med. 197(5): p. 611-620.

13.Burki, T. K., Burning issues: tackling indoor air pollution. Lancet. 377(9777): p. 1559-60.

14.Emmelin, A. and S. Wall, Indoor air pollution: a poverty-related cause of mortality among the children of the world. Chest, 2007. 132(5): p. 1615-23.

15.Fuentes-Leonarte, V., F. Ballester, and J. M. Tenias, Sources of indoor air pollution and respiratory health in preschool children. J Environ Public Health, 2009. 2009: p. 727516.

16.Rumchev, K., et al., Indoor air pollution from biomass combustion and respiratory symptoms of women and children in a Zimbabwean village. Indoor Air, 2007. 17(6): p. 468-74. 
17.Nandasena, S., A. R. Wickremasinghe, and N. Sathiakumar, Indoor air pollution and respiratory health of children in the developing world. World J Clin Pediatr. 2(2): p. 6-15.

18.Padhi, B. K. and P. K. Padhy, Domestic fuels, indoor air pollution, and children's health. Ann N Y Acad Sci, 2008. 1140: p. 209-17.

19.Cláudia Henrique da Costa, A. J. N. F., Rosa Maria Fernambel Marques e Silva, Thaís Ferrari da Cruz, Valeria de Oliveira Monteiro, Margareth Pio and Rogério Lopes Rufno, Alpha 1-antitrypsin deficiency in patients with chronic obstructive pulmonary disease patients: is systematic screening necessary? BMC Research Notes, 2019. 12(10).

20.Nakamura, H., Genetics of COPD. Allergol Int. 60(3): p. 253-8.

21.Wan, E. S. and E. K. Silverman, Genetics of COPD and emphysema. Chest, 2009. 136(3): p. 859-866.

22.Lutz, S. M., et al., Common and Rare Variants Genetic Association Analysis of Cigarettes per Day Among Ever-Smokers in Chronic Obstructive Pulmonary Disease Cases and Controls. Nicotine Tob Res. 21(6): p. 714-722.

23.van Gemert, F., et al., Socio-economic factors, gender and smoking as determinants of COPD in a lowincome country of sub-Saharan Africa: FRESH AIR Uganda. NPJ Prim Care Respir Med. 26: p. 16050.

24.Magitta, N. F., Epidemiology and Challenges of Managing COPD in sub-Saharan Africa Acta Scientific Medical Sciences, 2018. 2(1).

25.Lu, C. Y., et al., Oxidative stress associated with indoor air pollution and sick building syndrome-related symptoms among office workers in Taiwan. Inhal Toxicol, 2007. 19(1): p. 57-65.

26.Mondal, N. K., et al., Micronucleus formation, DNA damage and repair in premenopausal women chronically exposed to high level of indoor air pollution from biomass fuel use in rural India. Mutat Res. 697(1-2): p. 47-54.

27.Liu, Y., et al., Outdoor and indoor air pollution and COPD-related diseases in high-and low-income countries. Int J Tuberc Lung Dis, 2008. 12(2): p. 115-27.

28.Lalloo, U. G., et al., HIV and COPD: a conspiracy of risk factors. Respirology. 21(7): p. 1166-72.

29.Mahmood, T., et al., Prevalence and etiological profile of chronic obstructive pulmonary disease in nonsmokers. Lung India. 34(2): p. 122-126.

30.Ahmed, R., R. Robinson, and K. Mortimer, The epidemiology of noncommunicable respiratory disease in sub-Saharan Africa, the Middle East, and North Africa. Malawi Med J. 29(2): p. 203-211.

31.Magitta, N. F., Epidemiology of tobacco use and dependence in Sub-Saharan Africa: A systematic review. J Pulmonol Clin Res, 2018. 2(1). 
32.Lin, H. H., M. Ezzati, and M. Murray, Tobacco smoke, indoor air pollution and tuberculosis: a systematic review and meta-analysis. PLoS Med, 2007. 4(1): p. e20.

33.Lin, H. H., et al., Indoor air pollution from solid fuel and tuberculosis: a systematic review and metaanalysis. Int J Tuberc Lung Dis. 18(5): p. 613-21.

\section{Tables}

Table 1: Demographic characteristics of all responders who completed both the questionnaire and postbronchodilator spirometry 


\begin{tabular}{|c|c|c|c|}
\hline \multicolumn{2}{|r|}{ VARIABLE } & Frequency or & Prevalence or \\
\hline \multicolumn{2}{|r|}{ Age } & $52.16 \pm 11.59$ & $(34.01,91.33)$ \\
\hline \multirow[t]{2}{*}{ Gender } & Male & 340 & $33.30 \%$ \\
\hline & Female & 681 & $66.70 \%$ \\
\hline \multirow[t]{2}{*}{ Ethnicity } & African & 1017 & $99.61 \%$ \\
\hline & Other & 4 & $0.39 \%$ \\
\hline \multirow[t]{7}{*}{ Education (Self) } & Primary school & 751 & $73.56 \%$ \\
\hline & Middle school & 85 & $8.33 \%$ \\
\hline & High school & 7 & $0.69 \%$ \\
\hline & Some college & 22 & $2.15 \%$ \\
\hline & Four-Year College/University & 0 & $0.0 \%$ \\
\hline & No formal education & 147 & $14.40 \%$ \\
\hline & Unknown & 9 & $0.88 \%$ \\
\hline \multirow[t]{7}{*}{ Education (Father) } & Primary school & 387 & $37.90 \%$ \\
\hline & Middle school & 41 & $4.02 \%$ \\
\hline & High school & 5 & $0.49 \%$ \\
\hline & Some college & 17 & $1.67 \%$ \\
\hline & Four-Year College/University & 13 & $1.27 \%$ \\
\hline & No formal education & 379 & $37.12 \%$ \\
\hline & Unknown & 179 & $17.53 \%$ \\
\hline \multirow[t]{8}{*}{ Education (Mother) } & Primary school & 359 & $35.16 \%$ \\
\hline & Middle school & 21 & $2.06 \%$ \\
\hline & High school & 1 & $0.10 \%$ \\
\hline & Some college & 2 & $0.20 \%$ \\
\hline & Four-Year College/University & 2 & $0.20 \%$ \\
\hline & No formal education & 458 & $44.86 \%$ \\
\hline & Unknown & 178 & $17.43 \%$ \\
\hline & BMI & $25.13 \pm 5.70$ & $(12.49,62.5)$ \\
\hline \multirow[t]{4}{*}{$\overline{\text { BMI }}$} & Underweight $<18.5$ & 105 & $10.29 \%$ \\
\hline & Normal weight $=18.5-24.9$ & 442 & $43.33 \%$ \\
\hline & Overweight $=25-29.9$ & 279 & $27.35 \%$ \\
\hline & Obesity $=$ BMI $\geq 30$ & 194 & $19.02 \%$ \\
\hline \multirow[t]{2}{*}{ Smoking status } & Smokers & 158 & $15.48 \%$ \\
\hline & Non-smokers & 863 & $84.52 \%$ \\
\hline \multirow[t]{3}{*}{ Smoking status } & Non-smokers & 863 & $84.52 \%$ \\
\hline & Former smokers & 92 & $9.01 \%$ \\
\hline & Current smokers & 66 & $6.46 \%$ \\
\hline
\end{tabular}

Table 2: Association between chronic obstructive pulmonary disease (COPD) and selected risk factors 


\begin{tabular}{|c|c|c|c|c|c|}
\hline \multirow[t]{2}{*}{ Variable } & & \multicolumn{2}{|c|}{$\begin{array}{l}\text { COPD* Post Test } \\
\text { Results }\end{array}$} & \multirow[t]{2}{*}{ Total } & \multirow{2}{*}{$\begin{array}{c}\mathrm{p} \\
\text { value }\end{array}$} \\
\hline & & COPD PB & $\begin{array}{l}\text { No COPD } \\
\text { PB }\end{array}$ & & \\
\hline \multirow[t]{6}{*}{ Gender } & Male & 48 & 292 & 340 & 0.001 \\
\hline & & $14.12 \%$ & $85.88 \%$ & & \\
\hline & Female & 35 & 646 & 681 & \\
\hline & & $5.14 \%$ & $94.86 \%$ & & \\
\hline & Total & 83 & 938 & 1021 & \\
\hline & & $8.13 \%$ & $91.87 \%$ & & \\
\hline \multirow[t]{11}{*}{ Age } & 20.01 to 30 years & 0 & 0 & 0 & 0.005 \\
\hline & & $0.00 \%$ & $0.00 \%$ & & \\
\hline & 30.01 to 40 years & 10 & 151 & 161 & \\
\hline & & $6.21 \%$ & $93.79 \%$ & & \\
\hline & 40.01 to 50 years & 12 & 322 & 334 & \\
\hline & & $3.59 \%$ & $96.41 \%$ & & \\
\hline & 50.01 to 60 years & 14 & 237 & 251 & \\
\hline & & $5.58 \%$ & $94.42 \%$ & & \\
\hline & Over 60 years & 29 & 246 & 275 & \\
\hline & & $10.55 \%$ & $89.45 \%$ & & \\
\hline & Total & 65 & 956 & 1021 & \\
\hline \multirow[t]{8}{*}{ BMI } & Underweight <18.5 & 18 & 87 & 105 & 0.001 \\
\hline & & $21.69 \%$ & $9.28 \%$ & $10.29 \%$ & \\
\hline & $\begin{array}{l}\text { Normal weight }=18.5- \\
24.9\end{array}$ & 45 & 397 & 442 & \\
\hline & & $54.22 \%$ & $42.37 \%$ & $43.33 \%$ & \\
\hline & Overweight $=25-29.9$ & 11 & 268 & 279 & \\
\hline & & $13.25 \%$ & $28.60 \%$ & $27.35 \%$ & \\
\hline & Obesity $=30>$ & 9 & 185 & 194 & \\
\hline & & $10.84 \%$ & $19.74 \%$ & $19.02 \%$ & \\
\hline \multirow{12}{*}{$\begin{array}{c}\text { Level of } \\
\text { schooling }\end{array}$} & Primary school & 57 & 694 & 751 & 0.16 \\
\hline & & $68.67 \%$ & $73.99 \%$ & $73.56 \%$ & \\
\hline & Middle school & 5 & 80 & 85 & \\
\hline & & $6.02 \%$ & $8.53 \%$ & $8.33 \%$ & \\
\hline & High school & 2 & 5 & 7 & \\
\hline & & $2.41 \%$ & $0.53 \%$ & $0.69 \%$ & \\
\hline & Some collage & 2 & 20 & 22 & \\
\hline & & $2.41 \%$ & $2.13 \%$ & $2.15 \%$ & \\
\hline & None & 17 & 130 & 147 & \\
\hline & & $20.48 \%$ & $13.86 \%$ & $14.40 \%$ & \\
\hline & Unknown & 0 & 9 & 9 & \\
\hline & & $0.00 \%$ & $0.96 \%$ & $0.88 \%$ & \\
\hline \multirow[t]{4}{*}{ Smoking status } & Non smokers & 55 & 808 & 863 & 0.001 \\
\hline & & $66.27 \%$ & $86.14 \%$ & $84.52 \%$ & \\
\hline & Former smokers & 14 & 78 & 92 & \\
\hline & & $16.87 \%$ & $8.32 \%$ & $9.01 \%$ & \\
\hline
\end{tabular}


Table 3: Severity of chronic obstructive pulmonary disease (COPD) among patients according to Global Obstructive Lung Disease (GOLD) criteria

\begin{tabular}{lccccccc}
\hline GOLD class & $\begin{array}{c}\text { 30.01 to } \mathbf{4 0} \\
\text { years }\end{array}$ & $\begin{array}{c}\mathbf{4 0 . 0 1} \text { to } \mathbf{5 0} \\
\text { years }\end{array}$ & $\begin{array}{c}\mathbf{5 0 . 0 1} \text { to } \mathbf{6 0} \\
\text { years }\end{array}$ & $\begin{array}{c}\text { Above } \mathbf{6 0} \\
\text { years }\end{array}$ & Male & Female & Total \\
\hline Mild obstruction & 0 & 4 & 3 & 19 & 14 & 12 & 26 \\
\hline & $0.00 \%$ & $15.38 \%$ & $11.54 \%$ & $73.10 \%$ & $53.85 \%$ & $46.15 \%$ & $31.30 \%$ \\
\hline $\begin{array}{l}\text { Moderate } \\
\text { obstruction }\end{array}$ & 2 & 6 & 9 & 22 & 26 & 13 & 39 \\
\hline & $5.13 \%$ & $15.38 \%$ & $23.08 \%$ & $56.41 \%$ & $66.70 \%$ & $33.30 \%$ & $47.00 \%$ \\
\hline $\begin{array}{l}\text { Severe } \\
\text { obstruction }\end{array}$ & 0 & 2 & 1 & 11 & 6 & 8 & 14 \\
\hline & $0.00 \%$ & $14.30 \%$ & $7.14 \%$ & $78.60 \%$ & $42.90 \%$ & $57.10 \%$ & $16.90 \%$ \\
\hline $\begin{array}{l}\text { Very severe } \\
\text { obstruction }\end{array}$ & 0 & 0 & 1 & & & & \\
\hline & $0.00 \%$ & $0.00 \%$ & $25.0 \%$ & $75.0 \%$ & $50.00 \%$ & $50.00 \%$ & $4.80 \%$ \\
\hline Total & 2 & 12 & 14 & 55 & 48 & 35 & 83 \\
& $2.40 \%$ & $14.50 \%$ & $16.90 \%$ & $66.30 \%$ & $57.80 \%$ & $42.2 \%$ & $100 \%$ \\
\hline
\end{tabular}

Table 4: Prevalence of nicotine scoring and nicotine dependence among cigarette smoking respondents 


\begin{tabular}{|c|c|c|c|}
\hline Variable & & Frequency & Percent \\
\hline \multirow{10}{*}{$\begin{array}{l}\text { Fagarstrom Nicotine score } \\
\text { scale }\end{array}$} & 0 & 11 & $16.67 \%$ \\
\hline & 1 & 12 & $18.18 \%$ \\
\hline & 2 & 13 & $19.70 \%$ \\
\hline & 3 & 11 & $16.67 \%$ \\
\hline & 4 & 8 & $12.12 \%$ \\
\hline & 5 & 6 & $9.09 \%$ \\
\hline & 6 & 1 & $1.52 \%$ \\
\hline & 7 & 4 & $6.06 \%$ \\
\hline & 8 & 0 & $0.00 \%$ \\
\hline & Total & 66 & $100.00 \%$ \\
\hline \multirow[t]{4}{*}{ Nicotine dependency scale } & $\begin{array}{l}\text { Low to moderate dependency (Score } 0 \text { to } \\
4 \text { ) }\end{array}$ & 55 & $83.33 \%$ \\
\hline & Significant dependency & 11 & $16.67 \%$ \\
\hline & $($ Score $>=5)$ & & \\
\hline & Total & 66 & $100.00 \%$ \\
\hline
\end{tabular}

\section{Figures}

Living at home with a ciagarette smoker

Diagnosis of emphysema/bronchitis/COPD

Hospitalized for breathing problem $<10$ years

Operated for partial lung surgery

Tuberculosis

Lung cancer

Diabetes

Hypertension

Heart failure

Heart disease

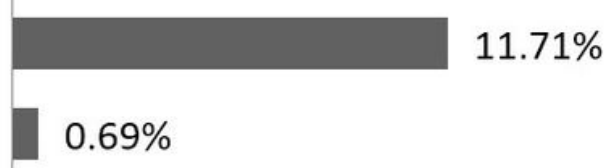

$1.96 \%$

$0.29 \%$

$5.31 \%$

$0.10 \%$

$4.60 \%$

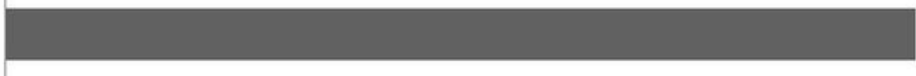

$24.49 \%$
$1.37 \%$

$4.80 \%$

Figure 1 
Distribution of co-morbidities among all respondents who completed questionnaire and spirometry

Exposure to dusty jobs for $\geq 1$ year

$36.76 \%$

Biomass fuel use for $\geq 6$ months

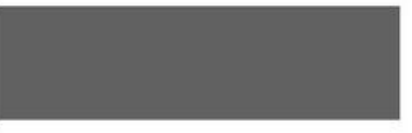

Cigarette smoking for $\geq$ year

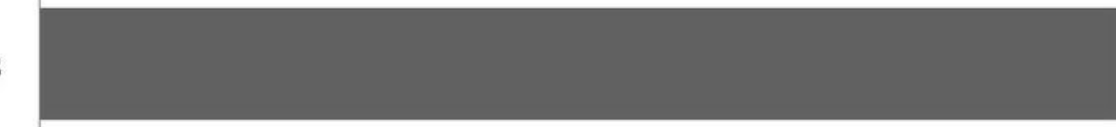

$98.35 \%$

$15.48 \%$

\section{Figure 2}

Prevalence of exposure to major risk factors for chronic obstructive pulmonary disease (COPD) among all respondents

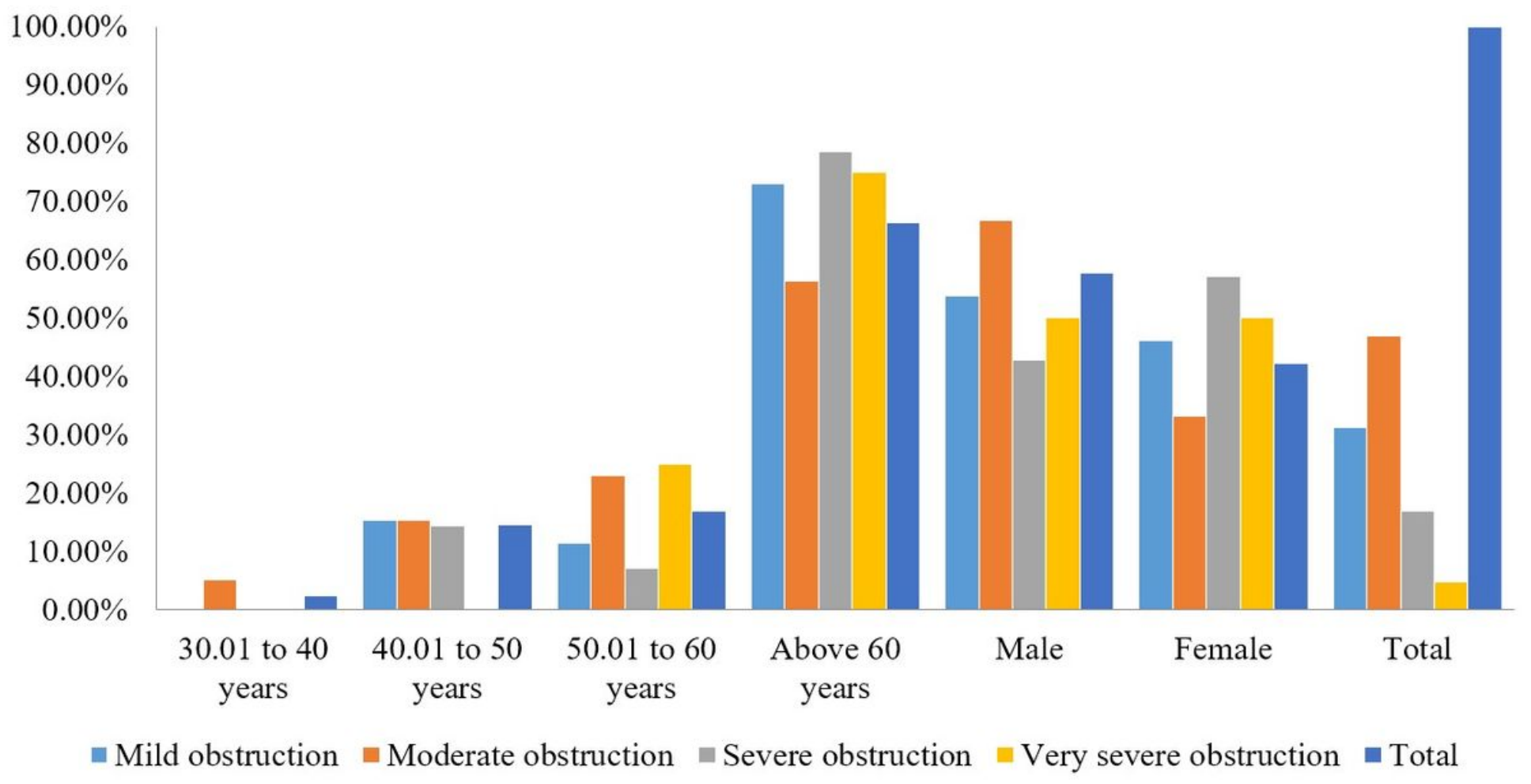

Figure 3 
Distribution of severity of obstruction among patients with chronic obstructive pulmonary disease (COPD) according to GOLD criteria.

$\because \mathrm{COPD} P \mathrm{~N}=\mathrm{No}$ COPD PB

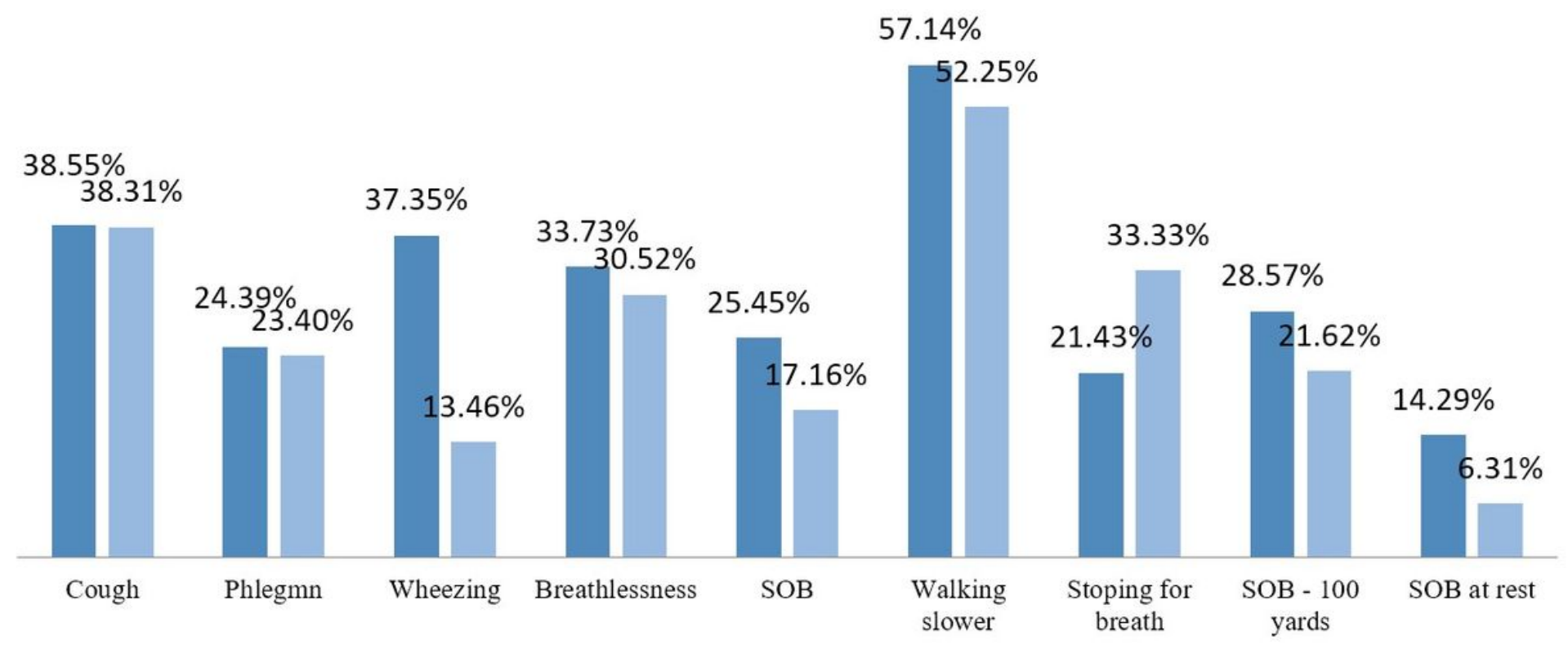

Figure 4

Prevalence of respiratory symptoms among patients with or without chronic obstructive pulmonary disease (COPD).

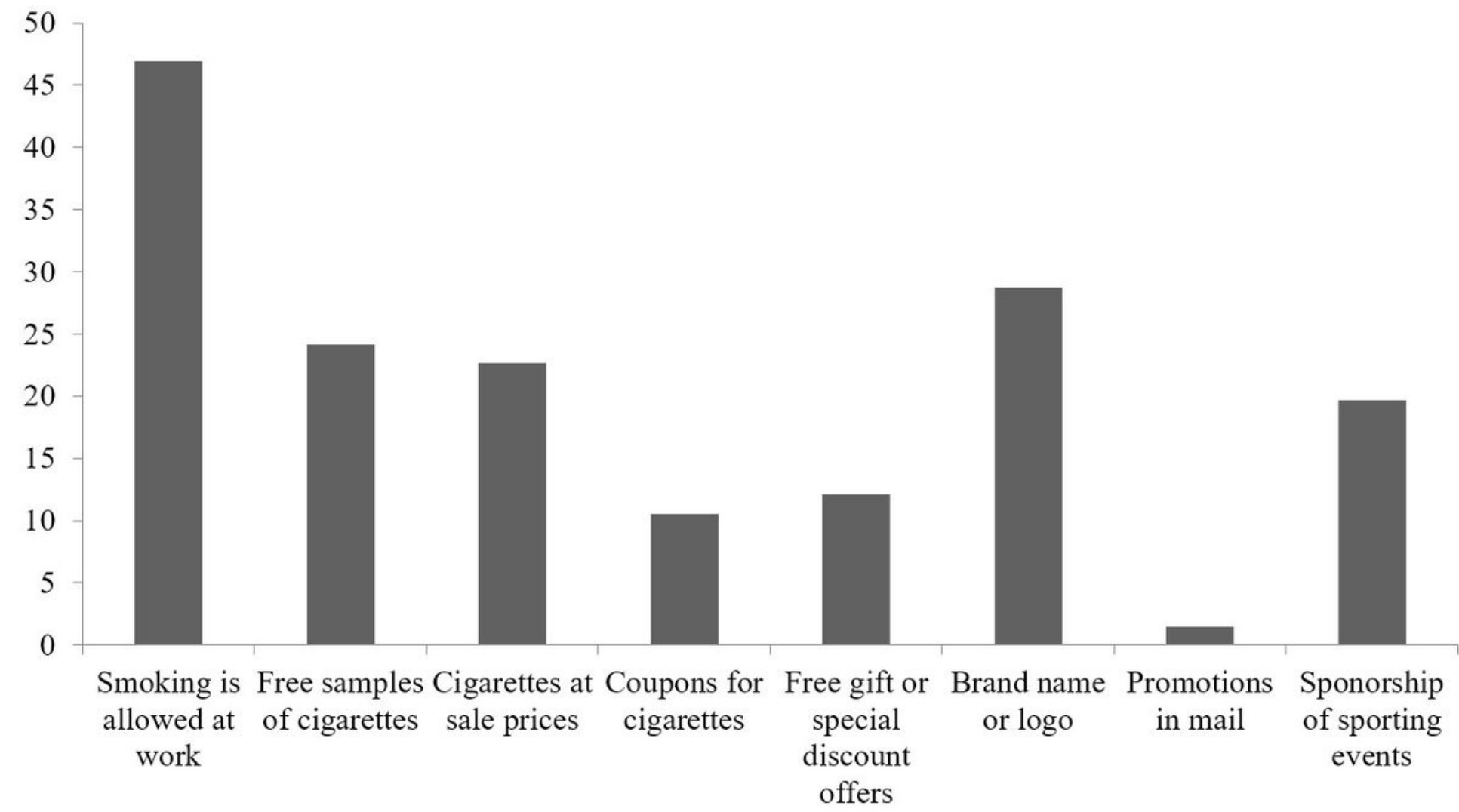


Figure 5

Prevalence of passive exposure to cigarette smoking and promotional activities in the study population. 